\title{
Memorias e imaginarios del ciclo pesquero entre los tripulantes industriales del puerto de Iquique, norte de Chile (1960-1990)
}

\section{Memories and imaginary fishing industry cycle between fishing crew the port of Iquique, northern Chile (1960-1990)}

Claudio Aguirre-Munizaga ${ }^{1}$ https://orcid.org/0000-0001-7378-2507

Carlos Mondaca-Rojas ${ }^{2}$ https://orcid.org/0000-0003-2640-2705

${ }^{1}$ Universidad de Tarapacá, Departamento de Educación, Iquique, CHILE. Email: caguirre@uta.cl

${ }^{2}$ Universidad de Tarapacá, Departamento de Educación, Iquique, CHILE.

Email: cemondacar@uta.cl

\section{Resumen}

La industria pesquera en Iquique pasó por distintos ciclos, de abundancia y escasez, principalmente por los vaivenes del mercado y la naturaleza, los cuales fueron marcando la industria a lo largo de su historia. Dentro de este contexto, se analizan las memorias e imaginarios sociales sobre esta nueva etapa económica de la región, a partir de sus actores principales, los pescadores industriales del puerto de Iquique (conocidos como "tripulantes"), tomando en cuenta el conjunto de prácticas, laborales y culturales, de clase y género. Inferimos que se conforman cuatro imaginarios colectivos de diferenciación instituidos desde la base de su especificidad laboral, la que va a estar supeditada por la transformación de la tecnología de extracción y del mercado (auge económico), generando nuevos cambios sociales entre los tripulantes y sus prácticas culturales heterogéneas.

Palabras claves: pesca industrial, tripulantes pesqueros, norte de Chile, imaginarios socioculturales.

\begin{abstract}
The fishing industry in Iquique went through different cycles of abundance and shortage, mainly by the vagaries of the market and the nature, which were marking the industry along its history. Within this context, we are analysing the reports and social imaginary on this new stage of the economic region, from its principal actors, the industrial fishermen from the port of Iquique (known as "crew"), and taking into account the set of practices, labor and cultural, class and gender. We infer that conform four imaginary collectives of differentiation introduced since the basis of its specificity of labor, which is going to be subject to the transformation of the mining technology and market (economic boom), generating new social changes among the crew and their cultural practices heterogeneous.
\end{abstract}

Keywords: industrial fishing, fishing crew, north of Chile, sociocultural imaginary.

Recibido: 3 enero 2017. Aceptado: 12 diciembre 2017 


\section{Introducción}

Los procesos de industrialización de la pesquería en el norte de Chile se incrementan desde mediados del siglo XX, debido a la expansión del capital transnacional que busca nuevos espacios de explotación, a causa de las medidas proteccionistas de los recursos naturales, ambientales y ecológicos en el Primer Mundo, que obligaron a los capitales empresariales a buscar nuevos territorios para la extracción de materia prima a bajo costo de producción. Respecto de la industria pesquera, según Wintersteen (2011), después de la Segunda Guerra Mundial existió una carrera por las riquezas ictiológicas (anchovetas y sardinas), las cuales sirvieron como materia prima para la elaboración de harina de pescado como alimento destinado al creciente aumento global de la industria de pollos, cerdos y la piscicultura en la época de posguerra.

En este contexto, los puertos de Chimbote en Perú e Iquique en Chile se transformaron rápidamente en los mayores centros mundiales exportadores de pesca industrial. Desde los ańos sesenta, esta ciudad se transforma en uno de los nodos con actividad pesquera más gravitantes en la economía local y nacional, debido a que con la intervención del Estado a través de la CORFO se implementa el Programa de Fomento Pesquero, ${ }^{1}$ que tendrá como objetivo central impulsar el desarrollo industrial del país fomentado por las agencias internacionales y nacionales.

En un informe de la época, la Organización de las Naciones Unidas para la Alimentación y la Agricultura (FAO) revela que la reserva demersal de la costa chilena supera con creces al actual stock de las costas del mar del norte y la reserva pelágica de la plataforma californiana (CORFO, 1959, p. 6). Lo anterior demuestra claramente de qué modo las agencias de desarrollo están implicadas en la promoción de la industrialización de las costas chilenas. Se inició un proceso de acumulación de conocimiento científico sobre las costas chilenas, la CORFO contrató una misión pesquera norteamericana, la United States Fisheries all

1 Lo anterior está inserto dentro de los planes de "desarrollo hacia adentro bajo la premisa desarrollista", a partir de la política de sustitución de importaciones centrada en la industrialización del país.
Wildlife Service, que actúa a lo largo de la costa del Pacífico desde Perú (1941) y Chile (1944-1947), realizando estudios de las especies que podrían ser comercializadas (Duhart y Weinstein, 1988, p. 35).

Estas políticas también apuntaban a desarrollar las regiones del norte del país, las cuales se encontraban en una evidente crisis que se venía arrastrando desde el declive de la industria del salitre. De acuerdo a Podestá (2004), el otrora dinámico puerto sobrevivía escasamente con el aporte de las dos únicas salitreras activas (María Elena y Victoria), de funcionarios públicos, contingente militar y un movimiento portuario asociado a una economía informal y al contrabando. Además, se crearon franquicias aduaneras que lograran la liberación de derechos para todos los materiales, equipos, maquinarias e instalaciones destinadas a ser aprovechadas por las industrias o las personas relacionadas con la pesca.

A partir del ańo 1953, se adoptan una serie de medidas que buscan promover el despegue económico, sobre todo de las ciudades de Arica e Iquique. Se promulga el DFL 303 que otorgó diversas franquicias tributarias y aduaneras que favorecieron directamente a la ciudad de Arica; ya para el año 1958 se dicta la Ley 13.039, que crea la Junta de Adelanto de Arica, la cual estaba destinada a promover el desarrollo social y económico de esta zona. Además, se crea el Comité Programador de Inversiones de Iquique y Pisagua. Asimismo, es necesario considerar la reducción substancial en los impuestos y la liberación del impuesto a la compraventa.

En el año 1960, el Ministerio de Agricultura y la CORFO otorgaron franquicias a la industria pesquera a través del DFL 266, lo que se traduce en que: "Se faculta al presidente de la república a otorgar franquicias aduaneras y tributarias que contempla específicamen te a las personas jurídicas que de alguna manera ejerzan o se dediquen a la construcción o reparación de embarcaciones adecuadas para la pesca industrial o comercial, queda claro también, que las personas que se acogen a este beneficio deben reinvertir sus utilidades hasta el 31 de diciembre de 1973" (Peña, 1964, p. 49, citado en Aguirre, 2014, p. 178), lo que se manifestó en una reducción substancial en los impuestos y la liberación del impuesto a la compraventa. 
Por otra parte, a partir de esta década, se crea el Instituto de Fomento Pesquero (IFOP), institución a través de la cual se generaron créditos por 3 millones de dólares con el fin de ir en ayuda de pescadores profesionales, armadores, pesqueros e industriales pesqueros, para adquirir botes pesqueros, motores marinos, redes e implementos de pesca, barcos pesqueros, equipos de instalaciones y construcción de obras civiles a los industriales (Peña, 1964, p. 46). Asimismo, hay que considerar las leyes 13.309 (Ley Arica) y 12.937 (Zona Franca Industrial para Iquique y Pisagua) en sus partes relativas a las exportaciones, las cuales permitieron que la industria en los años posteriores alcanzara un crecimiento explosivo.

En ese sentido Naser et al., (2009) plantean que el Plan Pesquero para Iquique marchó con un ritmo acelerado, en el que CORFO puso todos sus esfuerzos en esta zona ya que, según todos los estudios realizados por expertos internacionales, contenía una de las riquezas marítimas más grandes del mundo, tanto por la abundancia como por la variedad de especies. Al instalarse estas plantas surgen rápidamente problemas logísticos derivados de la escasez de mano de obra especializada (tripulantes), operadores de planta, enlatadores y rederas, problemas cruciales para poner en marcha la industria. Esta escasez de personas fue subsanada especialmente con la reconversión económica de sujetos provenientes de los barrios y caletas de pescadores fronterizos a las instalaciones industriales. Quienes, en palabras de Aguirre Díaz y Mondaca (2014, p. 180),

[a]portaron a la industria un preciado contingente con experiencia avalada en el trabajo pesquero; con elaborados saberes sobre el medio y técnicas apropiadas a su especificidad laboral. A ellos habría que sumar el enrolamiento de una heterogeneidad de sujetos (hombres y mujeres) que provenían de distintas trayectorias laborales, sectores sociales y de otras latitudes: ex salitreros, ex balleneros, marinos extranjeros, empresarios, agricultores provenientes del sur, entre otros. ${ }^{2}$

2 La implementación de ciertos modelos productivos se da en nodos geográficos interconectados, ya sea en el modelo productivo como en los modos culturales de consumo material y simbólico.
A finales de 1963 la industria sufre una nueva crisis, producto de las fluctuaciones del mercado y lo cambiante de la biomasa marina, lo que conllevó a la quiebra de las pesqueras más pequeńas, apareciendo sociedades de industriales más grandes, tales como: "Coloso y Guanaye. También surgen los complejos pesqueros de los Angelini: Iquique, Indo y Eperva. La industria pesquera se transforma "...en sociedades privadas y anónimas, bajo un criterio monopólico" (Duhart y Weinstein, 1988, p. 45). ${ }^{3}$ Durante el período del gobierno de la Unidad Popular, las industrias con mayor volumen de captura y capacidad de sus instalaciones pasarán a formar parte del área de propiedad social. Es decir, la expropiación de las industrias construidas sobre la base de la monopolización; aunque la poca efectividad en las gestiones y los vaivenes económicos, políticos y naturales impidieron que el proceso se llevara a cabo.

Para finales de la década de los setenta, producto de la política de libre mercado impuesta por el sistema económico implementado por la dictadura militar, se traspasaron todas las empresas estatales al sector privado. Con ello, la industria pesquera no escapa de la lógica del proceso neoliberal y rápidamente se comienza a concluir el proceso de monopolización comenzado en la década anterior. Junto con esto, se genera un importante repunte económico debido al incremento de la biomasa marina en el norte y a la apertura del país a importantes mercados para sus productos marinos.

Para 1977, la industria nuevamente entra en crisis, consecuencia de la sobreexplotación de la biomasa marina, sumado al desconocimiento de los ciclos reproductivos, además de la incidencia del fenómeno natural conocido como "El Nińo" producen que la principal especie pelágica, conocida como anchoveta, desaparezca de las costas chilenas. La evolución de la pesquería de cerco en la zona norte indica que esta se centró históricamente (1955-1973) sobre la anchoveta, cuyos desembarques mantuvieron niveles superiores al 95\% del total de recursos pelágicos hasta 1969, presentando fuertes fluctuaciones en 1965 y años posteriores para disminuir sus capturas en 1972-1973 y en 1977 por causas atribuidas a efectos combinados de condiciones ambientales

3 Además, aparece la inversión de capitales sudafricanos. 
adversas y de sobrepesca de un recurso compartido por la pesquería chilena y peruana (Martínez et al., 1987, p. 259).

La capitalización que se había generado durante la época de expansión económica en conjunto con la tecnología, además de los precios internacionales de los productos marinos, principalmente la harina de pescado, habían generado cierta resistencia a los embates de la crisis a partir del capital acumulado, además de los esfuerzos de pesca que apuntaron hacia la captura de sardina española. ${ }^{4}$ Ante la desaparición de la especie principal había que buscar una nueva que la reemplazara, ya que se debía mantener el incesante ritmo de producción. Así, se determinó que la sardina española sería el pez idóneo, ya que este se ajustaba a los diseños operacionales. Desde 1977 predomina la pesca de la sardina española, la que en esos últimos años había contribuido con alrededor del $70 \%$ de los desembarques, a excepción de 1983 en que alcanzó el 90\% (Martínez et al., 1987, p. 260).

Para la década del ochenta, la pesca industrial se había consolidado como la primera fuente de producción en la zona. Según datos de la Subsecretaría de Pesca de la época, el sector aportó en 1980 el $0,58 \%$ del producto geográfico bruto, aumentando en 1984 al 0,95\%. Por otra parte, la actividad industrial de procesamiento aportó en 1980 el 0,4 del PGBN (Producto Geográfico Bruto Nacional), aumentando en 1984 al 0,65\%. Para esta década la mayor flota industrial de la zona norte la posee la región de Arica y Parinacota, alcanzando en el año 1985, 176 embarcaciones, con una capacidad de captura de 1.062.000 toneladas y con una participación del $78,1 \%$ de la producción total del país. En lo que se refiere a empleos directos, alcanzó a 6.455 sujetos, representando el 6,8\% de la fuerza de trabajo de la zona y la actividad extractiva que fue de 3.749 personas, de las cuales 2.399 trabajaban en la pesca industrial (Cotroneo, et al., 1987, p. 142).

Como sabemos, este tipo de economías basadas en los recursos marinos estan condicionadas a los cambios climáticos, como también políticos que se han

4 La depredación de los recursos, énfasis en la actividad reductiva, y la dirección del producto hacia los mercados internacionales, es parte de la política económica actual. configurado en el proceso de implementación en el norte del país. Sin lugar a duda, este ciclo industrial significó para la región un repunte en su actividad económica. El imaginario del progreso se mantuvo sobre la base del ciclo salitrero, pero hay que dejar en claro que no todos participaron de igual manera en la abundancia de este ciclo, ni tampoco se debe obviar el daño ecológico que causó en la biomasa marina, debido a la depredación de las especies pelágicas, que definitivamente llevó a la crisis total de la pesca en los años noventa.

En este contexto de instalación e implantación de la industria pesquera en el norte de Chile, específicamente en el puerto de Iquique, surge como representación un colectivo humano conocido desde entonces con el nombre de tripulantes pesqueros, como mencionamos anteriormente, compuesto por sujetos provenientes de los barrios y caletas de pescadores fronterizos que se reconvierten económicamente y que pasan a conformar parte importante de la sociohabitabilidad del norte de Chile. Como grupo sociocultural parte de nuestra historia regional, nos interesa en este artículo analizar las memorias colectivas e imaginarios sociales de estos pescadores industriales del puerto de Iquique. Sostenemos que el conjunto de prácticas de su labor tiene connotaciones culturales representadas simbólicamente, las que les otorgaron imaginarios de diferenciación cultural y que fueron instituidos desde la base de su especificidad laboral, de grupo social y de género. En este sentido, planteamos la existencia de imaginarios y representaciones que tienen estos tripulantes acerca de su participación en la economía regional.

El primer imaginario es transversal a los otros; es el de la masculinidad, cuyo trabajo culturalmente es representado como trabajo para hombres, al cual podríamos denominar "estructural", pues es desde donde se construyen los otros imaginarios (subestructurales). De esta manera la masculinidad dominante se representa como diferencia de los otros trabajadores masculinos, debido a la especificidad del trabajo que ejercen como sujetos de trabajo de hombre de mar, trabajo duro, es decir, tarea solo de hombres.

El segundo imaginario es el de la abundancia, que tiene relación con el dinero que ganaron, dándoles 
una capacidad de gasto que permitió en la región nortina -entre otras cosas propias del desarrollo pesquero- un sostenido incremento del comercio de todo tipo como, por ejemplo, tiendas de vestir, bares, prostíbulos e incluso la venta de droga, cuyo principal cliente era el tripulante pesquero, que se convirtió en un personaje vital dentro de este tejido social.

El tercer imaginario es el del recuerdo esencialista de su trabajo en épocas de crisis del pasado y presente; conectando su memoria histórica con tiempos de bonanza al tratar de explicar cómo eran esos tiempos en los cuales su juventud no les permitió vislumbrar un futuro más promisorio o simplemente la resistencia a una sociedad utilitarista. La escasez da paso a la valoración de ciertas vivencias, en las que la memoria colectiva formada fue hilada en ciclos de abundancia de dinero, plasmándose como una herida, la cual debe sanar por medio de la resignificación del presente a partir del pasado, o viceversa.

El cuarto imaginario es el de la remembranza de la diversión y vida cotidiana que llevaban, prácticas dionisiacas que los marcaron fuertemente, como los lugares de diversión simbolizados como espacios vivenciados y resignificados. De esta forma, los recuerdos más significativos de un grupo están dados en los lugares más frecuentados por ellos como tropos socioculturales dentro de los discursos de los tripulantes, en los que la importancia del dinero en abundancia es gravitante como estructura dentro de los marcos de la memoria histórica de estos hombres de mar.

De acuerdo a lo anterior, se sostiene en este artículo que la memoria de estos trabajadores de la pesca vive de recuerdos colectivos que permiten comprender que desde la remembranza individual y desde la experiencia colectiva laboral puede hacerse inteligible la historia de estos trabajadores, como una construcción mediatizada entre los espacios de relaciones laborales y el mundo exterior, como lugares alegóricos a su mundo, lo que se manifestaría en la construcción de una memoria colectiva que pervive como imaginarios sociales de los pescadores industriales en nuestra zona norte de Chile. De esta forma, estos sujetos se van constituyendo como grupo con dinámicas diferenciadoras dentro y fuera del puerto y el mar como espacio de trabajo, en tanto que la labor realizada y la remuneración percibida les va a permitir mantener formas socioculturales particulares; y además acceder a nuevas formas diferenciadoras, a partir de los cambios económicos, sociales y culturales que se originan en Chile en la década de los ochenta, los que se van a mantener hasta el declive de la industria en la década de los noventa del siglo pasado.

\section{Metodología}

La presente investigación se desarrolló siguiendo un enfoque cualitativo, descriptivo y analítico, conjugando metodologías y técnicas de la antropología y de la historia, lo que nos permitió ampliar el campo de conocimiento sobre el tema de la industrialización de la pesca en el norte de Chile y las relaciones socioculturales que se construyeron a partir de este proceso. Desde esta perspectiva, podemos plantear que las metodologías cualitativas no tratan con objetos, sino siempre con acciones significativas hechas por sujetos concretos, de carne y hueso, que viven, sienten, aman, odian, imaginan, que tienen vivencias y maneras concretas de dotarlas de sentido. Por lo tanto, la relación entre el investigador y los sujetos investigados está basada siempre en términos intersubjetivos, lo que supone relaciones discursivas simétricas, en tanto que ninguna de las partes es menos subjetiva que la otra, y en efecto, más objetiva (Sebe, 1996; Martínez, 2000; Aguirre, 2011). Con esta orientación, la investigación indaga en las memorias e imaginarios sociales de los pescadores industriales. Dichas representaciones se pueden encontrar en su ámbito personal, como también en el ámbito colectivo, que se constituye en los marcos sociales del grupo.

Desde esta perspectiva, se emplearon dos estrategias de investigación. Por una parte, se analizaron antecedentes históricos sobre el proceso de inserción del capitalismo industrial en la pesca en la región de Tarapacá y específicamente en el puerto de Iquique, a partir del estudio y análisis de fuentes bibliográficas, como también de documentos pertinentes al proceso. Luego, se sistematizó la información recolectada con el fin de reconstruir el contexto histórico y social de la época. 
Asimismo, se efectuaron entrevistas en profundidad a un total de 12 informantes, que fueron identificados y seleccionados por medio de la colaboración del Sindicato de Tripulantes Pesqueros de la Ciudad de Iquique, que estuvieron muy interesados en apoyar la investigación. Para la mayoría de las entrevistas fueron los propios sujetos de estudio los que recomendaron a quienes entrevistar, en muchos de los casos en sus propias faenas en las lanchas en el puerto. Esta faceta metodológica permitió analizar en profundidad la vinculación entre lo temporal y lo espacial, relacionando el pasado con el presente, en que los sujetos entrevistados establecen una conexión entre la memoria individual y la colectiva, la cual está colmada de imaginarios en sus propias embarcaciones de trabajo (Pollak, 1992; Martínez, 2000). En este caso particular, los consentimientos informados a petición de los propios entrevistados no evidencian la confidencialidad, confirmando la idea de una memoria histórica esencialista que los representa, interés de dar a conocer su experiencia incluyendo sus nombres y apellidos y la función que tenían en su trabajo.

También se elaboró un registro con las observaciones de actividades, situaciones e interacciones significativas. De esta manera se busca comprender de primera mano las relaciones que se establecieron dentro de los espacios laborales, sean estos los barcos pesqueros, la industria en tierra o las faenas en los muelles. Igualmente, se indagó en las relaciones que se establecieron fuera de los lugares laborales, en aquellos espacios de sociabilidad que se generaron en la ciudad puerto de Iquique.

\section{Memoria histórica e imaginarios de los tripulantes pesqueros del norte de Chile}

La memoria no es una capacidad que tenga como fin lo verosímil, más bien es una función que no es igual en todos los individuos ni en los colectivos sociales. Lo interesante de la memoria, aparte del registro, es la capacidad de darle un sentido a lo que recordamos, manifestándose como parte de los procesos políticos, sociales y culturales que evidenciamos a lo largo de nuestra vida, que será lo que denominamos como memoria histórica, la que entenderíamos como la regeneración o reconstrucción de acontecimientos pasados que han sido vivenciados o significados y la vez resignificados por un grupo o colectivo humano determinado, dejando en claro que todo este proceso se realiza desde el presente, imaginando un pasado con todas las certezas e incertezas metodológicas y epistemológicas de la historiografía desde la historia oral (Halbwachs, 2002; Ricoeur, 2004).

Desde esta perspectiva, los recuerdos individuales no suceden en sujetos aislados, sino insertos en redes de relaciones sociales, institucionales y grupales. De esta manera la memoria histórica se relaciona con los imaginarios, puesto que estos serían aquellas representaciones construidas social y culturalmente, que permiten distinguir como real lo que en cada sociedad se considere realidad y que, además, estructuran en cada época la experiencia de procesos históricos específicos, generando tanto comportamientos como imágenes reales admitidas como realidad social plausible.

De esta forma, la memoria histórica está colmada de imaginarios sociales y culturales en el marco de contextos políticos, económicos, sociales y culturales específicos. Es decir, los imaginarios y la memoria son parte intrínseca de la historia de los grupos humanos, pues posibilita registrar, conservar y recordar experiencias, sean estas personas, cosas materiales e ideas que se relacionan e interactúan con imágenes, percepciones, acontecimientos, sentimientos, e incluso olores, que nos sitúan en un espacio y tiempo pasado en diálogo permanente con el presente. Así, la memoria histórica de los tripulantes pesqueros tiene la capacidad de darle sentido al recuerdo de su presencia en la industria pesquera como agentes que fueron parte del proceso histórico, social y cultural regional (Jelin, 2002; Candau, 2002).

En este contexto, estos recuerdos individuales no sucedieron en sujetos aislados, sino que estuvieron insertos en redes de relaciones sociales, institucionales y grupales de la industria pesquera regional, que cimentaron una memoria histórica de acuerdo a los marcos de recuerdos vivenciales desde donde construyen su discurso de una época en la que fueron actores principales en la comunidad regional. La memoria se convierte en colectiva cuando se sostiene 
sobre la comunicación del grupo y está organizada en marcos sociales, temporales y espaciales. Puesto que es a través de la memoria, las vivencias, las experiencias y los modos diversos en que los sujetos se apropian y usan su entorno y espacio social inmediato; se va otorgando un significado a los procesos sociales económicos, políticos y culturales (Todorov, 2000; Halbwachs, 2004; Nora, 2009).

En este sentido, la memoria histórica de estos actores de la pesca germina desde imaginarios colectivos como una representación de ser parte del proceso histórico y social de los puertos del norte de Chile, lo que permite la posibilidad de investigarlo, no solo desde el ámbito del desarrollo político y económico, sino ampliarlo a lo social y cultural. Pensamos que estos imaginarios se manifiestan en un primer momento como una representación construida en las labores y relaciones en la lancha, para de ahí entender su actuar en la sociedad local, donde estructuraron y generaron comportamientos particulares, como imágenes reales y como una realidad social plausible de ser estudiada. Lo que para Baczko (1991) serían aquellos imaginarios sociales resultantes de una producción colectiva, ya que esta funcionaría como depósito de la memoria que los grupos sociales acopian de sus contactos con lo cotidiano. En este sentido el imaginario social sería el conjunto de relaciones de imágenes que actúan como memoria afectiva social de una cultura. En este espacio es donde las diferentes percepciones de los sujetos sociales configuran una visión de sí mismos en relación a los otros.

\section{Tripulante pesquero, trabajo de hombres dentro de los hombres}

Un primer imaginario tiene relación con una suerte de ideal central (masculinidad) construido históricamente como base estructural desde lo masculino; a partir de ahí, será un imaginario donde el trabajo de pescador y todo lo concerniente a su labor es conformado desde la estructura social institucionalizada o normalizada en su labor y trabajo a partir de la dicotomía hombre/mujer, trabajo de hombre/ trabajo de mujer, etcétera. La memoria histórica de estos pescadores es una acción sobre el pasado que está constantemente en reconstrucción, en función del contexto social donde se emplace y articule el individuo. Así, un tripulante nos comentaba: "Nosotros comíamoh bien, teníamoh de todo aentro del barco, aparte de ganar más plata negociamos otros beneficios... Y sipo, habia sindicato de los tripulantes, los motoristah y los de patroneh (Roberto Castillo, motorista pesquero, 2011).

Es a partir de esta base que se construyen representaciones que conforman la memoria o las memorias. Podríamos hablar de un imaginario radical como figura de sentido, como núcleo central de un imaginario social más amplio. Es decir, cuando nos referimos a los tripulantes pesqueros, aludimos a los cimientos desde donde se construyen las representaciones de estos sujetos; y que a la vez le dan forma a la memoria colectiva local (Castoriadis, 1998).

Los relatos de los tripulantes mantienen la connotación inmanente de solo hombres en la lancha y en el mar, recordando el trabajo de pescador según el cual el uso de la fuerza física y la explicitación constante de los peligros a los que estaban expuestos son los principales recuerdos, como lo plantea Julio Rojas (tripulante pesquero, 2011): "El trabajo era peligroso, te ahogabai, podiai perder las piernas, se te cortaban los deoh. Un cabrito que llevaba tres meses perdió la pierna, la red cuando iba saliendo se la cortó, tenía veintitrés años. Recién se habia casado". Esto configuraría un imaginario periférico (Castoriadis, 1999) que se transforma de acuerdo al cambio de las condiciones laborales que se originan en la necesaria profesionalización y capacitación de su trabajo con la irrupción de la tecnología y la especialización, como también con los cambios producidos por los vaivenes políticos y económicos.

En este imaginario, el recuerdo de los tripulantes pesqueros está supeditado al concepto de masculinidad como imaginario radical, viéndose a sí mismos como hombres duros, puesto que el trabajo que desempeñan es solo para cierto tipo de hombres, dispuestos al sacrificio de largas jornadas y peligros que significa el trabajo pesquero, como lo expone Juan Ortega (tripulante pesquero, 2011): "No cualquiera era tripulante, una vez llegaron unos cabritos y se fueron altiro, no aguantaron el trabajo. Apenas estuvieron una semana a bordo y pidieron que los desembarcaran". Así, podemos observar esta autoimagen 
de hombres duros y arriesgados. A aquellos hombres no aptos para el trabajo, se los feminiza de diferentes maneras, como lo señala Ramírez:

Reconocer el proceso de construcción de la masculinidad es adentrarse en diversos campos, como el laboral, el familiar, pares, que ordenan su relación con base en una connotación de género. La masculinidad incide en el sujeto y lo transforma; éste, a su vez, posee elementos que pueden modificar la estructura social. De ahí que este concepto no pueda entenderse sino como una relación sujetoestructura indisoluble, en una dialéctica de la cual no es posible desligarse (Ramírez, 2005, p. 57).

Esta masculinidad se ve reflejada dentro del espacio de trabajo que es la lancha, como lo explicita Juan Ortega (tripulante pesquero): "Antes el trabajo pesquero era pesao, todo era a mano. Después llegaron los power y eso alivio harto la pega, los tripulantes antiguos, en broma nos dicen pescadores de agua dulce; Quién no pesca asi ahora" (Juan Ortega, 2011). De lo anterior, se puede observar que la forma de trabajo fue forjando una representación de sí mismos como hombres generando una suerte de demarcación de los otros dentro y fuera del grupo.

Como sabemos, los discursos pueden cambiar de acuerdo a los contextos históricos y socioculturales; así, el trabajo de pescador como trabajo de hombre va variando de acuerdo a las percepciones que se tienen de este y de los cambios en su concepción entre generaciones. Antes el trabajo de pescador era construido a partir de discursos como el uso de la fuerza física y los peligros a los que estaban expuestos estos hombres, configurando un imaginario que se transforma de acuerdo al cambio de las condiciones laborales que se originan en la estructuración del trabajo mismo (irrupción de la tecnología y la especialización), como también en las condiciones económicas que fueron también un elemento importante a la hora establecer los distintos imaginarios de estos sujetos.

\section{De la abundancia de ser y vivir como tripulante pesquero}

Los tripulantes pesqueros, debido al trabajo que desempeñaban, eran muy bien remunerados, lo que generaba para ellos una suerte de prestigio dentro de la sociedad del norte de Chile. Esto tuvo por efecto que fueran sujetos importantes en el ámbito económico, social y cultural regional. Vivir como tripulante significaba tener una amplia capacidad de gasto como recompensa a la naturaleza del trabajo, es decir, era parte de la construcción imaginaria de su oficio, trabajo de hombres: recompensas para hombres. Con ello los tripulantes pesqueros vivían y significaban su mundo en una suerte de presente continuo, rompiendo con la lógica del porvenir como sustento de lo útil. De esta manera, serían los imaginarios sociales los que ejercerían cierta influencia en las formas de pensar, juzgar e interactuar socialmente. Todo esto conformará la memoria colectiva de estos sujetos, la cual ciertamente se resignificará, de acuerdo a las experiencias posteriores de estos.

En este sentido, tenemos un segundo imaginario que tiene relación con la abundancia del dinero, con el que los tripulantes le dan sentido a su vida, aceptando las formas de interactuar socialmente y en las relaciones sociales de producción, entendiéndose como parte de estas, producto de su trabajo. Rolando Andrade (tripulante pesquero, 2011) al respecto observa que: "Ganábamos harta plata, en las tiendas nos recibian con las manos abiertas, porque sabian que ganábamos plata, mostrábamos la liquidación y nos daban créditos con las manos abiertas, esto nos pasaba en todos los lugares donde ibamos, a cachuines, fuente de soda, etcétera".

Lo anterior demuestra cómo los tripulantes estructuran o desestructuran desde su propia subjetividad los sistemas de vida compartidos y las formas de convivencia colectiva mediante la memoria, porque es la memoria cargada de imaginarios la que construye el sentido de la experiencia. De acuerdo a esto, los valores y el trabajo como institución construida juegan un papel importante, ya que identifican el mundo social donde los sujetos se mueven, simbolizando los imaginarios institucionalizados por la misma sociedad. Don Juan Abarca (tripulante pesquero, 2011) seńala que: 
El capitán que teníamos era bueno pa' pescar, entonces él ganaba cualquier plata igual que nosotros, entonces nos decía: "Ya cabroh, este fin de semana no va haber zarpe y se inventaba un zarpe imaginario, se encachan, vamos a ir tomar unos copetes, bailar y pasarla bien". Partíamos con el capitán, como éramos clientes, tanta plata, todas las niñas que estaban acá pa' nosotros, servíamos la mesa con puro whisky, bebida, picadillo y se cerraba el local.

El ideal periférico de los pescadores estaba dado por la abundancia, que servía como soporte de otros imaginarios en un momento dado. Si eras tripulante, tenías el privilegio de pasarlo bien, de gastar aquí y ahora. Ciertamente, estos discursos conformaron el imaginario de la pesca industrial en el norte de Chile. En este sentido, su recuerdo e imagen del pasado es dinámico, articula percepciones y experiencias de su realidad en un tiempo instituido como imaginario, que marca el tiempo social a partir de momentos importantes de la vida, momentos significativos que le dan sentido al tiempo en que viven. Rolando Andrade (tripulante pesquero, 2011) recordaba que: "Antes se ganaba plata, incluso con mi familia pa' las fiestas se invitaban a todos, yo pagaba, viajábamos cada quince días a Tacna".

De esta manera, los tripulantes les dan sentido a ciertas fases del tiempo vivido, es el significado que tiene para ellos recordar sus experiencias, las cuales están elegidas de acuerdo a lo que se quiere recordar. Por ello es que la percepción de los acontecimientos sociales no es un hecho dado, sino parte de la experiencia individual y social que, en cierta forma, está limitada a la capacidad de interpretar las relaciones sociales constituidas por los acontecimientos en los cuales ellos participan. En efecto, podemos plantear que los imaginarios de los tripulantes actúan como figuras interpretativas dentro de sus espacios simbólicos, que son plausibles frente a una determinada interpretación de la realidad social.

A partir de lo anterior, podemos entender que toda memoria colectiva es el recipiente donde se contienen los imaginarios, donde se articulan y se resignifican las interpretaciones de la realidad, dando sentido a la existencia de los sujetos dentro de un contexto sociohistórico determinado que trasciende el tiempo. Lo imaginario configura y estructura la realidad asumida y percibida por los sujetos sociales (Castoriadis, 1998; Castoriadis, 1999) Siendo así, la memoria colectiva de los tripulantes pesqueros está organizada en un primer tiempo dentro de los ciclos de abundancia, del ser y vivir como tripulante pesquero, donde germina la representación de la capacidad del gasto debido al acceso a dinero, lo que conlleva un imaginario de recordación de lo bien que les fue y que lo pasaron.

\section{La memoria e imaginarios de la escasez: "Ya no somos los mismos..."}

Un tercer imaginario de los tripulantes es representado por un segundo momento de la memoria colectiva de estos en una adecuación a los cambios producidos en su entorno, donde el desgaste de la actividad pesquera en un momento dado de la historia produjo nuevas significaciones que se tenían del pasado y que son nuevamente puestas en el discurso, pero desde otra óptica. En este caso, los momentos de abundancia pueden estimular ciertas sensibilidades y, a la vez, saturarlas. Podemos ver que los recuerdos e imaginarios de la escasez son la fase del replanteamiento de la memoria y de los imaginarios colectivos. No es la repetición de nada sobre el pasado, sino que es desde el presente de donde se reconfigura y se resignifica, a partir de situaciones concretas vivenciada por el grupo, como forma para comprender su presente.

Juan Ortega (tripulante pesquero, 2011) señala así: "Antes se ganaba plata, ahora no alcanza para nada. Igual nosotros tenemos la culpa, nunca ahorramos, todo era jarana y pasarlo bien". Por lo tanto, la memoria colectiva se genera a partir del aporte de memorias individuales (significadas de imaginarios), las cuales están insertas dentro de los marcos sociales del grupo: trabajo, familia, amigos, dinero, etcétera. José Ayala (patrón de pesca, 2011), refiriéndose a lo mismo nos plantea: "Hoy no hay garantías, cuando estaba la dictadura nos pagaban el feriado de treinta dias, el día domingo era inamovible. No trabajábamos, y si lo trabajábamos nos pagaban un bono de treinta mil pesos, y por las cargas más, nos pagaban todo". Entonces, la memoria, como los imaginarios, 
no son estáticos, más bien se van configurando en el devenir histórico y social, dependiendo de las vivencias de los sujetos y los significados que estos le otorguen a su realidad, ya sea en la abundancia como en la escasez (Durand, 1992).

En este sentido, nos referimos a los cambios en la producción y el trabajo, los cuales han marcado la memoria y los imaginarios de los tripulantes pesqueros. De acuerdo a esto, se observa que la memoria, como el imaginario social, se define siempre como representación plausible de su realidad, dando como resultado la acción de valoraciones construidas en lo simbólico. De esta forma, el imaginario se entrelaza con la memoria colectiva, porque el imaginario se construye social y temporalmente. Como señala Rufino Astudillo (tripulante pesquero, 2011): "Antes llegábamos a las tiendas y nos daban crédito altiro, ahora digo que soy tripulante ni me mean, ahora somos cachos, no pagamos".

Lo anterior demuestra cómo se van valorizando ciertas vivencias. La memoria colectiva formada en los ciclos de abundancia se plasma como una herida en el presente, la cual debe sanar por medio de la resignificación del presente a partir del pasado, o viceversa. El mismo tripulante nos confidenciaba que: "Igual nosotros tenemos la culpa, jamás nos preocupamos del futuro. Incluso muchos preferían que no les pagaran cotizaciones para ganar más plata". Podemos visualizar que en los momentos de escasez surge la culpa como catalizador del presente y como construcción de un imaginario agonístico, una autocrítica en la conciencia de la ley y el trabajo que acusa la transgresión; por lo tanto, como lo mencionamos anteriormente, el imaginario se construye a partir de bases, cimientos o imaginarios radicales, que otorgan una estructura a los imaginarios periféricos, a los discursos sobre sí mismos y el grupo (Castoriadis, 1999).

Desde esta óptica, el imaginario del tripulante pesquero (el nosotros) es visto positivamente en los tiempos de abundancia, y cambia en forma negativa en aquellos de escasez. Los discursos que se construyen en torno a lo segundo están basados en la culpa; el discurso sobre sí mismo y su propio trabajo es autocrítico. Juan Ortega (tripulante pesquero) corrobora esta apreciación con su relato: "Yo le digo a los cabros que no trabajen en esto, ya no se gana plata, a mi hijo lo mandé a estudiar pa' que tenga un mejor futuro, acá va puro a perder el tiempo arriba de los barcos, que estudie y se vaya a las minas, ahi está la plata ahora" (Juan Ortega, 2011). El discurso sobre sí mismo puede ser peyorativo, de igual modo la opinión desvalorizada que tiene de su propio trabajo. Aunque esto sea así, la imagen de hombres duros se mantiene, es decir, parte de los imaginarios periféricos van cambiando, pero se conservan algunos que los reafirman como sujetos diferentes a los otros. Esto es, su memoria opera como traspasos de imaginarios a las nuevas generaciones.

Esto se puede observar a partir de cómo la memoria se manifiesta en las relaciones que se forjan entre las distintas generaciones como mecanismo de transmisión de imaginarios propios de un grupo que se define como tal. Don Francisco (tripulante pesquero) afirma que: "Ahora los que ganan plata son los mineros, pero nuestro trabajo es más peligroso y ganamos menos, los viejos ganaban plata, ahora hay que trabajar más, hay que sacarse la cresta pa' hacer un buen sueldo" (Francisco Lara, 2011). De esta forma, el pasado no se conserva, se reconstruye a partir de la necesidad del presente, y esto solamente se origina en los marcos sociales de la memoria que entregan directrices de referencia a los sujetos dentro del espacio en que viven, convocando al pasado para justificar las representaciones del presente. Es decir, la memoria utiliza mecanismos de selección que mantienen algunos elementos y desechan u olvidan otros, siendo ambos procesos parte integrante de aquella. Asimismo, el olvido permite una apertura hacia el futuro, escapando a la repetición y reconfigurando la memoria del pasado (Yerushalmi, 1988).

El pasado es resignificado. En él los tripulantes no pueden olvidar situaciones positivas y negativas que se produjeron durante su vida. $\mathrm{Y}$ en el recuerdo transmitido a las nuevas generaciones, rememoran colectivamente aquellos hechos que apuntan al pasado glorioso y lo que significó en sus vidas haber sido parte de este proceso. Rolando Andrade (tripulante pesquero, 2011) confirma esta observación al plantearnos que: "Antiguamente no es como ahora, se trabajaba en armonia todo, no habia tanta veleidad como hay ahora, es por lo mismo que ahora la pega es más escasa, antiguamente trabajabai en armonía. Compartíamos todo, saliamos a tomar juntos, volviamos al barco juntos". 
De lo anterior se observa de qué modo la memoria del pasado se expresa no como una simple comunicación con el pasado o como repetición de este, sino más bien como una forma de recuperar las posibilidades de ser, como puerta hacia el futuro. Lo que Todorov (2000, p. 32) llama "memoria liberadora”, que permite utilizar el pasado con vista hacia el presente, aprovechar las lecciones de la vida para significar el presente. Los sujetos siempre mantienen expectativas sobre su futuro o, para este caso, el presente; la memoria permite levantar los logros realizados o no realizados en el pasado, resignificándolos hacia el futuro.

La memoria e imaginario de la escasez es la fase de replanteamiento de la memoria histórica y de los imaginarios colectivos. No es la repetición sobre el pasado, sino que es desde el presente desde donde se reconfigura y se resignifica, a partir de situaciones concretas vivenciada por el grupo, como forma de comprender su presente. Es precisamente esto lo que conlleva a analizar posteriormente su situación actual, es decir, los momentos de abundancia como promesas logradas que reafirman en cierta manera la memoria del grupo, en un presente de escasez.

Así, la memoria como los imaginarios se construyen en marcos de referencia sociales y es a la vez desde donde construimos nuestros discursos sobre la realidad. Ahora bien, estos discursos sobre la realidad objetiva o estructuras objetivas estarán dados siempre desde una posición subjetiva de autonomía, es decir, los momentos de escasez en los noventa que configuran el imaginario y la memoria de los tripulantes pesqueros hoy nos muestran cómo las estructuras sociales y los cambios en ellas configuran nuestra visión de la realidad; no en forma homogénea, sino heterogénea, ya que cada grupo tiene experiencias diferentes.

Podemos vislumbrar ciertas bases que configuran nuestra percepción de la realidad, lo que Castoriadis (1998) denomina "heteronimia en el dominio humano e histórico social”. De acuerdo con lo anterior, existen ciertos principios en los cuales los individuos están estructurados dentro de la institución social como cimientos que sostienen todo el sistema social de imaginarios y memorias, dentro de los cuales los sujetos sociales construyen su realidad. Aun- que no necesariamente estos andamiajes no puedan ser desmontados en acciones elucidianas -concepto utilizado por Castoriadis, que se refiere a la autorreflexión de los sujetos: pensar lo que hacen y saber lo que piensan, siempre desde un contexto histórico-, como lo plantea el mismo autor, sino como procesos de reflexión de los sujetos sobre lo que hacen, piensan y crean.

En este sentido, la memoria histórica es selectiva, es decir, se recuerda lo significativo para el grupo, tanto lo vivido en forma personal como los acontecimientos vividos por el grupo. Ni todo queda grabado ni todo queda registrado. Como tal, la memoria puede sufrir transformaciones en relación al momento en el cual es articulada, desde dónde está siendo expresada, desde un presente que ya no nos resulta un buen augurio. En cierta forma, se intenta comprender e interpretar el presente a partir de la memoria colectiva de estos sujetos, o sea, la memoria como fenómeno construido en forma consciente o inconsciente. De alguna manera el pasado y el presente presentarían cierta continuidad que se mediatiza a través de la memoria, como sentido de orientación del tiempo. De acuerdo a lo anterior, Juan Ortega (tripulante pesquero, 2011) nos decía que: "En los ochenta donde más se ganó plata, los viejos cerraban los cahuines, con todas las minas adentro, ahora no alcanza, los de ahora se van a Tacna".

Es interesante notar cómo la memoria se construye en una suerte de dialéctica entre presente y pasado, intentando que esa relación fluya en forma constante. Ya no es el mismo tiempo, pero si se resignifica en el presente como continuidad, el pasado no se encuentra desligado del presente y el acto de memoria contrae una relación dialógica en los tiempos en que el pasado puede configurar el presente, o viceversa.

\section{De la diversión y la vida cotidiana en el mundo popular de los tripulantes pesqueros}

Un cuarto imaginario tiene relación con los procesos de diversión en los que la memoria de los tripulantes no funciona como un mero archivo; más bien es un proceso dinámico de narraciones que forma parte de la dimensión social. La memoria individual en esta 
categoría del placer es una referencia de la memoria colectiva, y esta cambia según el lugar que los sujetos ocupan; y ese mismo lugar cambia de acuerdo a las relaciones que se mantienen en otros espacios, en tanto individuos que recuerdan en cuanto que son miembros de un colectivo. Es así como la memoria individual se interrelaciona con la memoria colectiva.

Es interesante notar que esta memoria colectiva está basada en el imaginario del dinero como uno de los tantos marcos que la conforman. Podríamos decir que el dinero como símbolo procuró la base de las estructuras de jerarquías y privilegios frente a los otros (mujeres u otros hombres). El valor que le otorgaban apuntaba a un medio de intercambio, no estaba destinado a la acumulación; es decir, el dinero no otorgaba prestigio por sí solo, sino por la forma en que se gastaba o se donaba. Podemos decir que el dinero como objeto y los usos de este como significantes e intermediarios de las relaciones de intercambio no se extinguen simplemente en el beneficio económico. Juan Abarca (tripulante pesquero, 2011) se refiere a esta situación de la siguiente forma: "Me acuerdo cuando recibi mi primer sueldo, yo pensaba que era poco, ya que trabajaba como pistola haciendo reemplazo. Llegué a la pieza y me tiraba la plata en la cara, nunca habia visto tanta plata; imaginate uno era pobre, yo trabajaba desde los doce años en la mar como pescador artesanal y nunca habia visto tanta plata".

Lo anterior se ha construido a partir de fenómenos significativos para los tripulantes pesqueros, sean estos sociales, culturales o históricos, sobre la base de la interpretación y reconstrucción que los propios sujetos hacen de ellos. Carlos Salgado (tripulante pesquero, 2011) nos contaba que: "Nos íbamos con todo el cuerpo, algunos con todo el sueldo, llenábamos las mesas con cerveza, cerrábamos los locales con todas las minas adentro, algunos se quedaban hasta dos días". La función del gasto, en este sentido, conlleva la idea de pérdida total. Irse con todo el cuerpo y con todo el sueldo, para muchos resulta inquietante, denota una acción irresponsable dentro de la lógica del trabajo productivo. Pero el gasto no apunta al consumo y la producción, más bien a la destrucción de energías y no a su acumulación.
Es por esto que el trabajo que ellos realizan como actividad humana de producción y conservación considera un excedente, el que es gastado en forma improductiva. De acuerdo a lo antes mencionado, la actividad de estos sujetos varía entre lo útil y lo inútil, esto último como forma de derrochar el excedente y satisfacer el deseo del gasto improductivo. Don Julio (tripulante pesquero) se refiere con esto a de qué modo no se pensaba responsablemente, al recordar que: "Yo me compré una casa cuando estaba más viejo, uno no pensaba después, total se ganaba plata, uno era joven. Lo único en que se pensaba era en pasarlo bien" (Julio Rojas, 2011).

Los tripulantes pesqueros fueron los actores principales de esta manera de vivir el presente, rompiendo con las lógicas de utilidad, buscando en la inutilidad su continuidad como seres humanos, el aquí y ahora como forma de existencia. Sin embargo, este derroche o gasto improductivo e irresponsable genera formas de prestigio dentro de los puertos del norte de Chile. Este dar en forma ostentosa va a construir cierta imagen del tripulante como exitoso, privilegiado, pero también como sujeto ignorante y derrochador.

Esto, visto con el ojo del sentido de lo útil (Bourdieu, 1998), los pasatiempos y el consumo frugal surgirían como mecanismos de distinción social destinados a mantener cierto estatus dentro del grupo, generando distancia con los otros. Eso sí, este autor no aclara cuándo el consumo se desvía de la satisfacción de necesidades diarias hacia el gasto improductivo, que también genera reconocimiento social (Potlatch) o simplemente placer (éxtasis dionisíaco). Lo anterior no resulta necesariamente irracional, ya que implica una necesidad real de diferenciación.

Don José (patrón de pesca) recuerda al respecto: "Cuando era pescador artesanal ni los pescaban por pobres, cuando era tripulante pesquero las mujeres llegan solas, pero no sabian na' con los conchesumares que se estaban metiendo" (José Ayala, 2011). De esta manera, podemos entender que la vida humana pasa; por un lado producir y acumular y, por otro, consumir y derrochar. Don Rolando (tripulante pesquero) nos confidenciaba que: "Yo nunca lo voy a negarlo, era bueno pa' tomar. Nosotros estábamos tomando y loh iban a buscar a la fuente de soda para embarcarnos, 
igual habia que trabajar, pa' después seguir tomando con las minas" (Rolando Andrade, 2011).

Estos ejemplos nos pueden ayudar a entender cómo la producción y adquisición están subordinadas al gasto, ya que el dinero como adquisición, en tanto que poder adquirido por ella, está direccionado hacia la pérdida o donación, pues es ahí donde se alcanza el prestigio y el reconocimiento. Sin lugar a duda, para el tripulante pesquero el acto de gasto y derroche era la forma mediante la cual se llegaba al prestigio en la sociedad, escapando a la lógica de la acumulación burguesa que ha establecido la condición del gasto restringido. Absi (2011) lo define del siguiente modo:

Para los hombres, esta inconmensurabilidad se confunde con la magnanimidad. Los salarios se perciben en efectivo y los hombres pasan a menudo directamente del cobro al burdel. Pocos vienen solos y la sociabilidad que tiene lugar alrededor de las mesas generalmente es la del trabajo. Invitar una ronda, apropiarse de la mujer más bella, o pagar servicios para sus empleados, permite reafirmar un estatus superior. Gastar y en consecuencia dejarse robar sin fijarse demasiado, es lo mínimo que se espera de alguien que pretende actualizar su rango y las relaciones de dependencia en el trabajo. Como el trabajo, la magnanimidad es también una calidad esencial de la masculinidad (p. 13).

Ahora bien, estas formas de gasto improductivo, fiestas, borracheras y sexo fuera de la reproducción suponen una evidente subversión simbólica hacia la cultura dominante burguesa, racional y utilitarista. Respecto de esto, revisemos algunos recuerdos de un tripulante pesquero:

Cuando llegábamos, lo primero que haciamos era encerrarnos en los cabarets, una vez llegamos a un cabaret donde habia una prostituta y un maricón, haciendo colas, colas hacian. Al maricón le hacian chupete. El maricón se llamaba Soledad, ique cante la Soledad! ¡Que cante la Soledad! y el maricón cantaba "Con un lunar en la ventana". Llegábamos como a las once de la mañana, más cañoneados y sin ningún peso, incluso [es]tuvimos presoh, estábamos en un cabaret y votaron a todas las prostitutas, y se quedaron con los puros maricones bailando, y estas nos acusaron a los pacos y nos llevaron presos (Julio Rojas, 2011).

Esta vida desenfrenada, el acceso a la excitación de los placeres corporales grotescos, la alta promiscuidad sexual forman parte del gasto improductivo o el consumo dionisíaco, como transgresión a la estructura productiva y reproductiva, como acto de soberanía, fueron parte del imaginario de los tripulantes. En términos prácticos Bataille (1996) sugiere que:

La risa, las lágrimas, la poesía, la tragedia y la comedia y más generalmente toda forma de arte que implique aspectos trágicos, cómicos o poéticos, el juego, la cólera, la embriaguez, el éxtasis, la danza, la música, el combate, el horror fúnebre, el encanto de la infancia, lo sagrado cuyo aspecto más ardiente es el sacrificio, lo divino y lo diabólico, el erotismo (individual o no, espiritual o sensual, vicioso, cerebral o violento, o delicado), la belleza, el crimen, la crueldad, el espanto, el asco, representan en su conjunto las formas de efusión de la soberanía (p. 91).

En este sentido, los tripulantes pesqueros se despojan del mundo del trabajo y la ley, de los límites, experimentando la transgresión, el despilfarro y el exceso, con el fin de escapar al orden productivo y utilitario basado en la prohibición de la satisfacción del deseo, frente la ley, la cual subordina el presente al futuro. La soberanía estaría centrada fuera de la utilidad racional de la acumulación y el ahorro, y el proyecto planteado por este, más bien está entrelazado con el presente, lugar en el cual no existe el cálculo racional del futuro, colocando la discontinuidad en contra de la continuidad; ya que la continuidad del trabajo exige generar proyectos de vida, lo que se traduce en sujetos basados en el cálculo y el ahorro. Pero como sabemos, en nuestra sociedad podemos encontrar restos de gastos improductivos que nos llevan a los placeres, a la orgía, al exceso, los que transgreden y trascienden la estructura del intercambio racional e instrumental, como la configuración 
del imaginario hedonista de los tripulantes pesqueros de Iquique.

\section{Comentarios finales}

De acuerdo a los cuatro imaginarios relevados en esta investigación y que conforman la memoria histórica de los tripulantes pesqueros del norte de Chile, podemos plantearnos que los contextos estructurales económicos, en un momento dado, condicionan -pero no determinan- la forma en la cual estos sujetos imaginan y a la vez construyen una memoria colectiva de acuerdo a la empírea impregnada en sus cuerpos y en sus memorias. No debemos olvidar que los sucesos que vivenciaron estos sujetos no están dentro de una dimensión totalizadora de las experiencias compartidas, sino que esta depende de la ubicación social dentro de un grupo y la del propio grupo, entendiendo que existen memorias colectivas dentro de una misma unidad o generación. A pesar de lo planteado, podemos visualizar que estas islas memorísticas se conectan a partir de un imaginario radical como es la masculinidad, que enlaza estas vivencias generacionales configurando una representación de estos sujetos en términos universales.

En ese sentido, podemos observar que los tripulantes pesqueros interpretan y reinterpretan su realidad resignificándola con su presente. Pero, según sean las condiciones en las cuales se encuentran, su experiencia con su entorno y su época, abundancia y escasez, para este caso, posibilitan la acción sobre la heteronimia a partir de la autonomía o soberanía, entendiéndose esto como fugas desde lo homogéneo a lo heterogéneo. Así, podemos plantear que nada es absoluto en el sentido de que las prácticas culturales de estos sujetos sean cambiantes. $\mathrm{O}$ sea, no es a partir de la escasez que los tripulantes pesqueros cambian totalmente sus formas de vida (fiestas, borracheras, excesos, gastos improductivos, entre otros; estos solo disminuyen), ya que según lo planteado por Bataille (1996), necesariamente para que ocurra el excedente debe existir la acumulación, no como fin sino como medio para que se produzca el gasto como expresión de soberanía.

En el plano de lo homogéneo los momentos de crisis o la idea de escasez hacen que surja la culpa por la transgresión, el futuro como proyecto, la ley y el trabajo como condicionamiento del ser humano. En este sentido Rufino Astudillo nos señalaba que: "Igual nosotros tenemos la culpa, jamás nos preocupamos del futuro. Incluso muchos preferían que no les pagaran cotizaciones para ganar más plata" (Rufino Astudillo, tripulante pesquero, 2011). Por lo tanto, el tripulante actual debe ahorrar lo suficiente ante la amenaza de la falta de recursos. Asimismo, para el tripulante pesquero surge la idea de elaborar un proyecto de vida que contemple el ahorro. Lo anterior demuestra el péndulo de vivir y gastar, lo útil y lo inútil, los límites de la transgresión y la culpa, la construcción del imaginario hedonista y agonístico, como forma jánica de la sociedad. Este ir y venir conformaría la memoria e imaginarios colectivos del tripulante pesquero industrial del puerto de Iquique.

En definitiva, cada imaginario representa la forma como se configura una tripulación, las relaciones sociales que se construyen a bordo de un barco, el modo de trabajo, los aprendizajes, la llegada de la tecnología a la labor pesquera y cómo estos sujetos iban interpretando sus experiencias en torno al ciclo a partir de sus espacios de relaciones en el trabajo y en el puerto. Estas relaciones están configuradas desde su subjetividad, su autoimagen y la de los otros, configurando sus imaginarios y memorias colectivas.

Lo anterior marca un ciclo como producción de relaciones sociales, la jerarquización de la sociedad iquiqueña sobre la base del prestigio que traía consigo trabajar en la pesca industrial como elemento simbólico de diferenciación. Producto de la posición económica de estos sujetos, el dinero, las mujeres, las fiestas, el derroche como símbolo de estatus $\mathrm{y}$, posteriormente, la pérdida de este a partir de la escasez configuran un discurso de pérdida y de lamentaciones; pero también de fortaleza para seguir manteniendo sus propios imaginarios ante la llegada de otros sujetos que vienen a cubrir cierto espacio dentro la sociedad iquiqueńa: del ciclo de la pesca al ciclo de la minería. 


\section{Agradecimientos}

Artículo resultado del Proyecto FONDECYT de Iniciación 11190353 y del Proyecto de Investigación Mayor de Ciencia y Tecnología de la Universidad de Tarapacá. Código 6710-15. Se agradece el apoyo del Convenio de Desempeño Regional UTAMINEDUC 1401.

\section{Referencias citadas}

Absi, P. (2011). De la Transgresión a la Subversión. El Valor del Dinero en los Prostíbulos de Bolivia. En Pavez, J. y. Kraushaar, L. (Eds.). Capitalismo y Pornología. La Producción de los Cuerpos Sexuados (pp. 379-403). San Pedro de Atacama: Ediciones Qillqa - Universidad Católica del Norte.

Aguirre, C. (2011). Imaginarios sociales en el puerto de Iquique en la Memoria de los pescadores industriales (1960-1990). Tesis para a optar al grado de Magíster en Antropología. Universidad Católica del Norte. Antofagasta, Chile.

Aguirre, C. et al. (2014). De pescador artesanal a tripulante pesquero. Pesca industrial y transformaciones sociales en Tarapacá. Norte de Chile (1950-1990). Intersecciones en Antropología, 15, 177-185.

Baczko, B. (1991). Los Imaginarios Sociales - Memorias y Esperanzas Colectivas. Buenos Aires: Nueva visión.

Bataille, G. (1987). La Parte Maldita. Espańa: Icaria.

Bataille, G. (1996). Lo que Entiendo por Soberanía. Barcelona: Paidós.

Bourdieu, P. (1997). La Distinción, Criterios y Bases Sociales del Gusto. Madrid: Taurus.

Candau, J. (2002). Antropología de la Memoria. Buenos Aires: Nueva visión.

Castoriadis, C. (1998). Hecho y por Hacer. Pensar la Imaginación. Buenos Aires: Eudeba.

Castoriadis, C. (1999). La Institución Imaginaria de la Sociedad. Buenos Aires: Tusquets.

CORFO (1959). Memoria institucional. 1939 - 1959. 20 años de labor. CORFO.
Cotroneo, M. y Díaz, M. (1987). Estrategia de desarrollo del sector pesquero de la zona norte de Chile. En Arana, P. (Comp.). Manejo y desarrollo pesquero. Valparaíso: Universitaria.

Duhart, S. y Weinstein, J. (1988). Pesca industrial: Sector estratégico y de alto riesgo. Santiago: Estudios sectoriales.

Durand, G. (1992). Las Estructuras Antropológicas de lo Imaginario. Espańa: Taurus.

Halbwachs, M. (2002). Fragmentos de la memoria colectiva. En http://atheneadigital.net/article/download/52/52.

Halbwachs, M. (2004). La Memoria Colectiva. Zaragoza: Prensa Universitaria.

Jelin, E. (2002). Los Trabajos de la Memoria. Buenos Aires: Siglo XXI.

Martínez, C. et al. (1987). Situación actual de la pesquería de Sardina espańola en la zona norte de Chile. En $M a-$ nejo y desarrollo pesquero. Arana, P. (Comp.). Valparaíso: Universitaria.

Martínez, M. (2000). Historia, memoria y paisajes en torno a la presa de Valle de Bravo (1940-2000). Instituto de Investigaciones. México: Dr. José Mora.

Nazer, R. et al. (2009). Historia de la Corporación de Fomento de la Producción CORFO 1939-2009. CORFO.

Nora, P. (2009). Pierre Nora en Les lieux de mémoire. Santiago: LOM.

Peńa, G. (1964). Aspectos económicos de la provincia de Tarapacá. En Memorial del ejército de Chile No 332. Diciembre 1964.

Podestá, J. (2004). La Invención de Tarapacá: Estado y desarrollo regional en Chile. Universidad Arturo Prat.

Pollak, M. (1992). Memoria e identidad social. Río de Janeiro: Estudios Históricos.

Ramírez, J. C. (2005). Madejas Entreveradas. Violencia Masculinidad y Poder. Varones que ejercen violencia contra sus parejas. Guadalajara: Universidad de Guadalajara - Plaza y Valdés.

Ricoeur, P. (2004). La Historia, la Memoria, el Olvido. México: Fondo de Cultura Económica. 
Sebe, J. (1996). Tres Alternativas metodológicas: historia de vida, historia temática y tradición oral. México: INAH.

Todorov, T. (2000). Los Abusos de la Memoria. Buenos Aires: Paidós.

Wintersteen, K. (2011). Fishing for Food and Fodder: The Transnational Environmental History of Humboldt Current Fisheries in Peru and Chile since 1945. Durham, NC: Duke University Press.

Yerushalmi, Y. (1988). Reflexiones sobre el Olvido. Usos del Olvido. Buenos Aires: Nueva visión. 